This is the peer reviewed version of the following article: [X. A. Jeanbourquin; A. Rahmanudin; A. Gasperini; E. Ripaud; X. Yu et al. : Engineering the self-assembly of diketopyrrolopyrrole-based molecular semiconductors via an aliphatic linker strategy. J. Mater. Chem. A. 2017. DOI : 10.1039/C7TA00896A.], which has been published in final form at [https://dx.doi.org/10.1039/C7TA00896A]. This article may be used for non-commercial purposes in accordance with RSC Terms and Conditions for Self-Archiving.

\title{
Engineering the self-assembly of diketopyrrolopyrrole-based molecular semiconductors via an aliphatic linker strategy
}

Xavier A. Jeanbourquin, Aiman Rahmanudin, Andrea Gasperini, Emilie Ripaud, Xiaoyun Yu, Melissa Johnson, Néstor Guijarro and Kevin Sivula*

The solid-state self-assembly of molecular semiconductors is a key aspect for controlling the optoelectronic properties of organic electronic materials. Herein, we investigate the use of a flexible linker strategy to control the self-assembly of a solution-processable diketopyrrolopyrrole semiconductor coded as $\mathrm{DPP}(\mathrm{TBFu})_{2}$. Two distinct dimers - prepared with varied linker position relative to the orientation of the conjugated core-reveal the effect of connectivity on the solid-state self-assembly and optoelectronic properties-favoring either $\mathrm{H}$ - or J-type aggregation. The dimer with a "vertical" linker orientation exhibits a poor crystallinity in neat films, but improves hole mobility in OFETs 10 -fold, reaching $3.0 \times 10^{-3} \mathrm{~cm}^{2} \mathrm{~V}^{-1} \mathrm{~s}^{-1}$ when used as an additive in with DPP(TBFu) 2 . Distinctively, the dimer with a "horizontal" linking orientation does not enhance charge carrier transport, but is found to affect the thermal stability of donor:acceptor blends in OPVs with PCBM. Devices retain $90 \%$ of their initial conversion efficiency after 5 hours of thermal stress, compared to only $45 \%$ for control devices. Thermodynamic and kinetic rationale further suggest that this flexible linker strategy represents a powerful tool to control supramolecular assembly in molecular semiconductors without altering the nature of the core conjugated segment.

\section{Introduction}

Solution processable molecular organic semiconductors have emerged as a promising family of low-cost materials for application in the roll-to-roll manufacturing of electronic and optoelectronic devices such as field effect transistors, organic photovoltaics, and light emitting diodes. ${ }^{1,2}$ The molecular structure of a typical solution-processable organic semiconductor consists of a $\pi$-conjugated semiconducting core together with flexible side chains to afford solubility. The ability to rationally design and construct variations of these components using organic chemistry facilitates the optimization of semiconducting energy levels and processability, which gives organic semiconductors an attractive advantage over many other materials. ${ }^{3-5}$ Nevertheless, the ultimate optoelectronic performance of any molecular semiconductor based device is dictated by its supramolecular self-assembly in the solid-state, which in turn is strongly influenced by $\pi-\pi$ interactions between the conjugated segments. These intermolecular interactions have proved quite challenging to predict $^{6}$ and to control ${ }^{7}$ independent of altering the semiconducting core. Moreover, phenomena such as structural polymorphism, ${ }^{8-13}$ defect formation, ${ }^{14-16}$ strain, ${ }^{17}$ and domain orientation/grain boundaries ${ }^{18-21}$ have been identified as additional complications that confound the rational engineering of molecular semiconductors. Thus developing generalizable tools to improve our understanding and ability to control the supramolecular self-assembly of organic semiconductors independent of altering the core $\pi$-conjugated unit is an important goal. 22,23

Researchers have already begun to address this objective using process engineering based techniques ${ }^{24}$ such as forcing directionality and/or spatial confinement during solution casting, which can influence polymorphism ${ }^{13}, 25-27$ and the crystal domain size/orientation. ${ }^{28,} 29$ Processing additives such as inert polymers or small molecule nucleation promotors have also been shown to influence the self-assembly of molecular semiconductors. ${ }^{11}$, 30 While these processing-based techniques have shown an encouraging level of control, they are essentially extrinsic, i.e. they can be greatly affected by external factors like substrate, solvent, evaporation rate, and are not generalizable towards arbitrary molecular structures. In contrast, routes for controlling molecular self-assembly by engineering the solubilizing side chains can preserve the electronics of the semiconducting core. ${ }^{31}$ This route has been widely investigated for $\pi$-conjugated polymers, ${ }^{32-38}$ and to lesser extent for small molecule organic semiconductors. ${ }^{39-42}$ Indeed, since the selfassembly of a typical molecular semiconductor with standard aliphatic solubilizing chains is dominated by $\pi-\pi$ interactions, 
side chain engineering offers limited control. Including heteroatoms to promote hydrogen bonding, ionic coordination, or other specific interactions can offer increased influence over the self-assembly, but can also alter the electronic properties potentially leading to the introduction of trapping states. ${ }^{31}$

Recently, a promising strategy to control supramolecular assembly without altering the semiconducting core has been suggested via the covalent tethering of conjugated segments with flexible non-conjugated chains. ${ }^{43-46}$ Indeed, employing flexible linkers in conjugated polymer systems-which break continuous backbone conjugation-have already shown promising effects by easing chain rigidity, increasing processability, and offering unique self-assembly motifs. ${ }^{47-54}$ In contrast, when flexibly linking small molecule semiconductors, $\pi-\pi$ stacking can be hindered due to the conformational restrictions, which can alter crystal domains size leading to more isotropic charge transport, and increased thermal stability of the solid-state morphology. ${ }^{43}, 44$ Melt processing was even recently demonstrated with this approach. ${ }^{55}$ Despite these encouraging results with the flexible linker approach, a clear understanding of the mechanism by which these flexibly-linked molecular systems affect intermolecular self-assembly is lacking. Thus, in order to develop this approach towards a functional tool to control supramolecular assembly in molecular semiconductors, more insight into the details of the effect is needed. Herein we employ a model molecular semiconductor system and different linking strategies to prepare two distinct dimers with the same conjugated core. The effect of the linker positions on the optoelectronic properties and self-assembly are scrutinized from both thermodynamic and kinetic perspectives.

\section{Results and Discussion}

To investigate the effects of the covalent linking strategy for controlling the self-assembly of solution-processable molecular semiconductors, we choose 6-bis(5-(benzofuran-2-yl) thiophen- 2-yl)-2, 5-bis (2-ethylhexyl) pyrrolo [3, 4-c] pyrrole-1, 4-dione (commonly coded as DPP $(\mathrm{TBFu})_{2}$ ) as the model $\pi$-conjugated unit. Diketopyrrolopyrrole (DPP) based small-molecules, especially $\mathrm{DPP}(\mathrm{TBFu})_{2}$, have been reported as promising electron donor molecules for organic photovoltaics (OPV) when used in combination with phenyl-( $\mathrm{C}_{61}$ or $\left.\mathrm{C}_{71}\right)$-butyric acid methyl ester (PCBM) as an electron acceptor, ${ }^{56}$ and their self-assembly into well-ordered crystalline domains is known to have an important effect on the device performance. ${ }^{57}$

Two dimers based on DPP $(\mathrm{TBFu})_{2}$ were synthetized using an unbranched aliphatic chain as a linker between the two conjugated segments. A horizontally linked dimer, coded $\mathrm{H}$ $(\mathrm{DPP})_{2}$, was connected at the 5-benzofuran position, while a vertical connection in the dimer coded $\mathrm{V}-(\mathrm{DPP})_{2}$ occurs at the imide position where the branched solubilizing chain normally resides. Scheme 1 shows the structure and synthetic strategy to prepare the two dimers. $\mathrm{H}-(\mathrm{DPP})_{2}$ was synthesized based on modified procedures from previous work on an aliphaticallylinked DPP $(\mathrm{TBFu})_{2}$ polymer. ${ }^{44}$ For the asymmetric coupling of one benzofuran group onto the dibromominated $\mathrm{DPP}(\mathrm{T})_{2}$ core (1), we found that the typical Suzuki coupling conditions strongly favoured the di-functionalized DPP(TBFu $)_{2}$ even when only one equivalent of the borylated benzofuran was used. ${ }^{58}$ However, using a Stille coupling method with polar aprotic DMF as a solvent instead of the conventional non-polar toluene together with the stannylated benzofuran (2), gave high yield of the mono-benzofuranated product, likely due to the role of DMF as a catalytic inhibitor. ${ }^{59}$ The subsequent symmetric coupling of this mono-functionalized DPP with 1,6-bis(2(trimethylstannyl)benzofuran-5-yl)hexane (3) gave the $\mathrm{H}-(\mathrm{DPP})_{2}$ dimer (4). On the other hand, the $\mathrm{V}-(\mathrm{DPP})_{2}$ dimer was synthesized by first linking two mono-alkylated $\mathrm{DPP}(\mathrm{T})_{2}(\mathbf{5})$ units via an alkylation with a $\mathrm{C}_{10}$ aliphatic chain at the imide position. The product was subsequently coupled using a Suzuki coupling with excess borylated benzofuran (6) to give the vertically linked $\mathrm{V}$-(DPP $)_{2}(\mathbf{7})$. Full synthetic details are given in the Electronic Supplementary information (ESI).

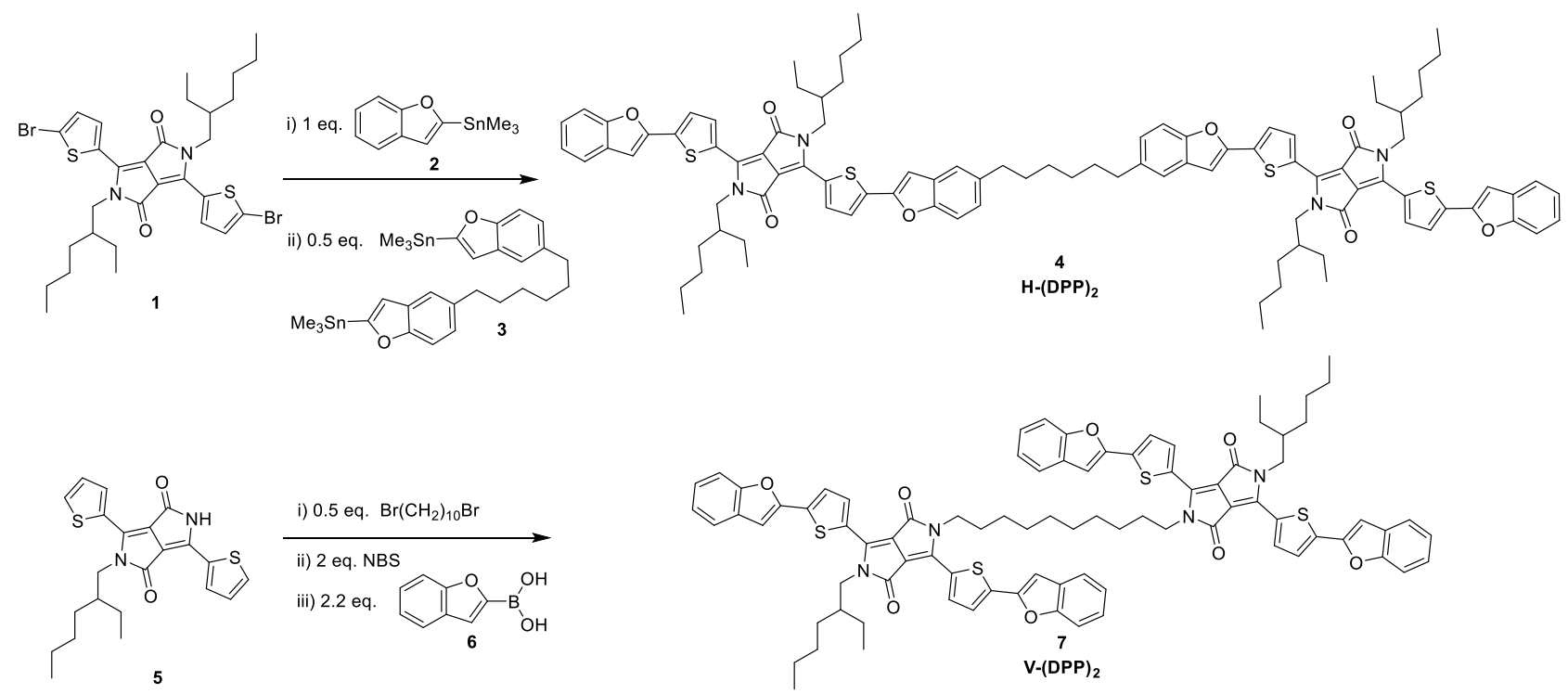

Scheme 1. Chemical structures and synthetic strategy of the novel DPP $(T B F u)_{2}$ based dimers, $V-(D P P)_{2}$ and $H-(D P P)_{2}$. 
Normalized UV-vis absorption spectra of the two dimers as well as the parent monomeric DPP $(\mathrm{TBFu})_{2}$ (coded as M-DPP hereafter) dissolved in chloroform are shown in Figure 1a. The three molecules have identical absorption spectra in solution, which is in good agreement with previously published data for the parent M-DPP. ${ }^{56}$ Indeed, aliphatic substituents are not expected to greatly affect the electron density of the conjugated core. In the solid state UV-Vis of the dimers cast from chloroform into thin films, the $\mathrm{V}-(\mathrm{DPP})_{2}$ dimer exhibits a spectrum qualitatively similar to the M-DPP (see normalized spectra Figure 1b). However, we note the presence of an increased background signal and broader peaks-likely stemming from poor film formation of the $\mathrm{V}$-(DPP $)_{2}$ due to its relatively low solubility (ca. $1 \mathrm{mg} \mathrm{mL}^{-1}$, compared to $>20 \mathrm{mg} \mathrm{mL}^{-}$ 1 for the horizontally-linked dimer or M-DPP), which results in the presence of aggregates in the film. Considering the horizontally-linked dimer, while the absorption peaks of $\mathrm{H}$ $(D P P)_{2}$ in the solid state appear at similar wavelengths and with similar peak widths compared to M-DPP, a clear change in the relative peak intensities is noted. The peak at $560 \mathrm{~nm}$ of $\mathrm{H}$ $(D P P)_{2}$ shows a relative decrease in intensity compared to $M$ DPP, whereas the peak at $665 \mathrm{~nm}$ exhibits an increased relative intensity. This change in solid state absorption between M-DPP and $\mathrm{H}-(\mathrm{DPP})_{2}$ suggests a possible difference in the solid-state self-assembly motif.
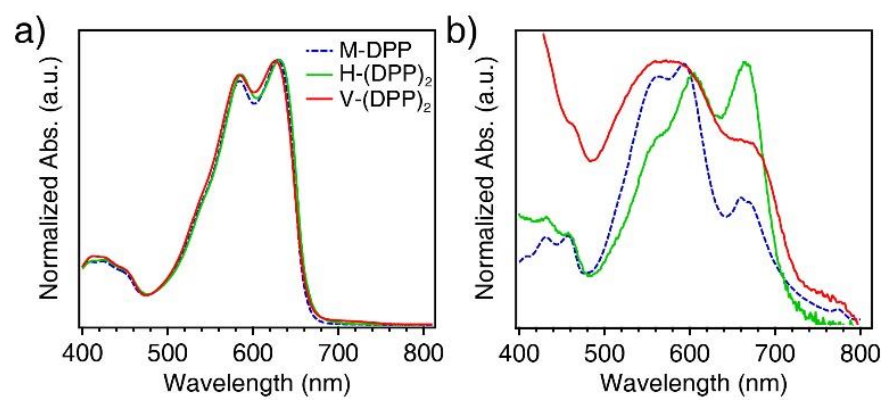

c)

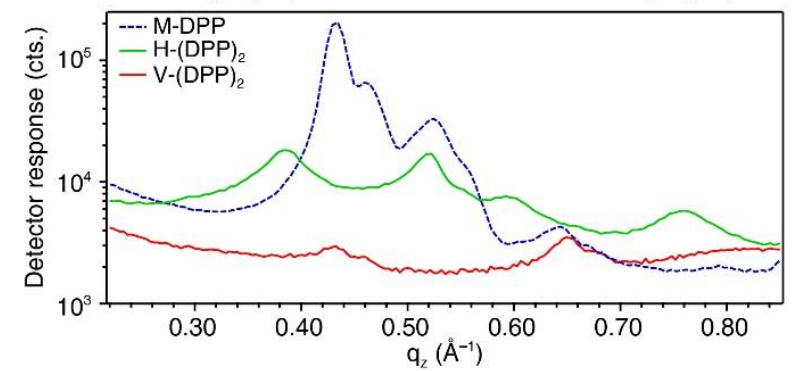

Figure 1. UV-Vis and crystallographic characterization. The normalized optical absorption spectra measured in chloroform solution (a) and in solid state thin films (b) are shown for the parent M-DPP, and the two dimers $\mathrm{H}-(\mathrm{DPP})_{2}$ and $\mathrm{V}-(\mathrm{DPP})_{2}$. (c) Out-of-plane grazing incidence $\mathrm{X}$-ray diffractograms of $\mathrm{M}$-DPP, $\mathrm{H}$-(DPP $)_{2}$ and $\mathrm{V}$-(DPP $)_{2}$ obtained from chlorobenzene drop-casted films.

In order to further investigate a possible change in selfassembly or crystal packing of the dimer molecules compared to the parent M-DPP, grazing incidence $X$-ray diffraction (GIXRD) was performed on solid state thin films prepared by dropcasting. The resulting out-of-plane diffractograms are shown in Figure $1 \mathrm{c}$ where M-DPP exhibits a primary peak at a scattering vector value of $q_{\mathrm{z}}=0.435 \AA^{-1}$, which is in good agreement with previous reports. ${ }^{60}$ This primary peak has been assigned to the (020) reflection corresponding to a stacking distance of $14.4 \AA$ between layers of overlapped ( $\pi-\pi$ stacked) M-DPP molecules separated by the solubilizing alkyl chains. ${ }^{61}$ We note that the scattering peak for the reported $\pi-\pi$ stacking distance (ca. 3.5 $\AA$ A) is typically not sufficiently intense to be observed in thin film XRD measurements. The $\mathrm{V}-(\mathrm{DPP})_{2}$ dimer exhibits a peak at a similar $q_{z}$ value compared to the primary M-DPP peak, suggesting that the vertical linking strategy does not affect the interplanar stacking distance. However, we observe a drastically smaller scattering intensity by almost two orders of magnitude despite similar film thickness, implying a significantly reduced crystallinity. An interplanar stacking peak is also observed for the $\mathrm{H}-(\mathrm{DPP})_{2}$ dimer, however, at a lower $q_{\mathrm{z}}$ value of $0.39 \AA^{-1}$ (stacking distance of $16.1 \AA ̊$ ). This larger interplanar stacking distance is surprising given that the solubilizing alkyl chains are identical in the M-DPP and the $\mathrm{H}-(\mathrm{DPP})_{2}$. However, this difference together with the additional peaks at $q_{z}=0.60$ and $0.76 \AA^{-1}$ support the notion of a unique molecular self-assembly in the $\mathrm{H}$-(DPP) ${ }_{2}$ dimer thin film. We note that the intensity of the scattering was also one order of magnitude lower than the $M$ $D P P$, suggesting a decrease in crystallinity similarly with the $V$ $(\mathrm{DPP})_{2}$ dimer.

The different supramolecular self-assembly of the $\mathrm{H}-(\mathrm{DPP})_{2}$ dimer implied by the GIXRD results is consistent with the solidstate UV-Vis results, considering previous studies of M-DPP and similar molecules. Indeed, in previous work from Nguyen and co-workers the authors suggest that the relative magnitude of the $665 \mathrm{~nm}$ optical absorption peak is inversely correlated to the amount of intermolecular $\pi-\pi$ stacking interactions in $M$ DPP films (since this peak decreased with annealing temperature relative to the peak at $590 \mathrm{~nm}) .{ }^{56}$ Moreover, previous work with a set of similar (monomeric) DPP-based molecules with varying units substituting the benzofuran (e.g. triphenyl amine or pyrene) reported a similar trend in the UVVis data compared to our $\mathrm{H}$-(DPP $)_{2}$ dimer. ${ }^{62}$ A pyrenefunctionalized DPP molecule in that work exhibited a very strong self-assembly due to its planarity, while the more bulky structure of a triphenyl amine derivative was suggested to hinder the $\pi-\pi$ stacking. Interestingly, their optical absorption data indicate the presence of a strong peak around $650 \mathrm{~nm}$ for the triphenyl amine derivative, whereas this peak is negligible in the case of the pyrene-substituted DPP. This observation further reinforces the view that the presence of the UV-Vis peak at $665 \mathrm{~nm}$ is either due to a decreased amount of $\pi-\pi$ stacking or to an increased $\pi-\pi$ stacking distance. However, if this peak only was attributed to a larger disorder within the film (decreased amount of $\pi-\pi$ stacking), we would expect the $V$ $(D P P)_{2}$ dimer to exhibit a stronger relative absorption at $665 \mathrm{~nm}$ compared to $\mathrm{H}$-(DPP) $)_{2}$ due to its drastically lower crystallinity implied by the GIXRD results. As this is not the case, an altered $\pi-\pi$ stacking of the $\mathrm{H}-(\mathrm{DPP})_{2}$ dimer is thus likely the cause of the altered UV-Vis spectrum. More specifically, the $\mathrm{H}-(\mathrm{DPP})_{2}$ dimer reasonably self-assembles with a different overlap of the $\pi$ conjugated cores compared to M-DPP. Indeed, other DPP-based 
molecules have been reported to self-assemble with varying amounts of co-existing $\mathrm{H}$-aggregate and J-aggregate character within the structure, which strongly affects their optical absorption properties. ${ }^{63}$ The hypsochromic shift observed in $\mathrm{M}$ DPP when going from solution to solid state (e.g. from $580 \mathrm{~nm}$ to $560 \mathrm{~nm}$ ) is typically ascribed to the direct overlap of the $\pi$ conjugated cores ( $\mathrm{H}$-aggregation). On the other hand, the bathochromic shift leading to the peak at $665 \mathrm{~nm}$ in solid state is characteristic of staggered overlap (J-aggregation). Therefore, even though both the M-DPP and $\mathrm{H}-(\mathrm{DPP})_{2}$ exhibit combined $\mathrm{H}$ and J-aggregate character, the self-assembly of $\mathrm{H}$-(DPP $)_{2}$ likely consists of more staggered overlapping nature compared to the parent M-DPP, which would explain both the reduced absorption at $560 \mathrm{~nm}$ and the strong peak at $665 \mathrm{~nm}$. We note that while it is common for J-aggregates to exhibit a narrower absorption peak with higher extinction coefficient and smaller Stokes shift compared to $\mathrm{H}$-aggregates, the apparent broadness of the peak at $665 \mathrm{~nm}$ is caused by the overlap of transitions that can be resolved by deconvolution (See Figure S1, ESI). Moreover, a smaller stokes shift observed in fluorescence emission measurements in $\mathrm{H}$-(DPP $)_{2}$ films compared to M-DPP films (100 nm versus $145 \mathrm{~nm}$ ) corroborates the self-assembly hypothesis (See Figure S1c, ESI).

A possible origin for the different solid-state behaviour of the $\mathrm{H}$ $(D P P)_{2}$ dimer implied by results discussed above could be due to intramolecular interactions between the two conjugated cores of the $\mathrm{H}$-(DPP $)_{2}$ dimer, (i.e. folding on itself). To investigate this possibility we measured the UV-vis spectrum of $\mathrm{H}-(\mathrm{DPP})_{2}$ in solution with increasing amounts of a non-solvent $(\mathrm{MeOH})$ at very low concentrations to promote intramolecular selfassembly. The UV-Vis data (shown in Figure S2a, ESI) shows that the intensity of the peak at $665 \mathrm{~nm}$ increases with the $\mathrm{H}-(\mathrm{DPP})_{2}$ concentration, suggesting that this peak arises from intermolecular rather than intramolecular self-assembly. Moreover, insight into the self-assembly mechanism of $\mathrm{H}$ $(D P P)_{2}$ in methanol can be obtained by plotting the aggregation fraction in function of the concentration as previously reported. ${ }^{64}$ This data (see Figure S2b, ESI) shows that the selfassembly follows a cooperative mechanism as opposed to an isodesmic model, indicating a nucleation and growth mechanism.

To further investigate the different solid-state behaviour of the dimers relative to the parent M-DPP, we next examined the compounds by differential scanning calorimetry (DSC). Figure 2 shows the second heating and cooling curves of the pure materials as well as blends of M-DPP containing different ratios of the dimers. The parent M-DPP (Figure 2a) exhibits an endothermic transition onset at $224^{\circ} \mathrm{C}$ when heating at $10{ }^{\circ} \mathrm{C}$ $\mathrm{min}^{-1}$ while an exothermic transition begins at $206{ }^{\circ} \mathrm{C}$ during cooling, attributed to, respectively, melting and crystallization. Scans of the vertically linked dimer (Figure $2 b$ ) show no detectable thermal transitions, consistent with a poor crystallinity suggested by the GIXRD results, and suggests that the vertically linking strategy prevents the conjugated core selfassembly in the solid state leaving only an amorphous film. In contrast, we did observe phase transitions with the horizontally linked dimer. The first heating scan of $\mathrm{H}-(\mathrm{DPP})_{2}$ (Figure $2 \mathrm{c}$, broken line) after preparing the sample via drop casting from chloroform shows an endothermic transition at $186^{\circ} \mathrm{C}$, considerably lower than M-DPP (note that no difference in melting temperature was noted in M-DPP between the first and second scans). Upon cooling, a weak exothermic transition was observed at $147^{\circ} \mathrm{C}$. The subsequent $\left(2^{\text {nd }}\right.$ ) heating scan (solid line Figure 2c) exhibited an exothermic transition starting at $121^{\circ} \mathrm{C}$ followed by an endothermic transition at a temperature of $165^{\circ} \mathrm{C}$. This behaviour suggests that a kinetically limited crystallization occurs when cooling the melt at $10^{\circ} \mathrm{C} \mathrm{min}^{-1}$. Indeed, upon increasing the cooling rate from 1 to $100^{\circ} \mathrm{C} \mathrm{min}^{-1}$, the subsequent heating scan shows an increase in the enthalpy of the exothermic transition (see ESI Figure S3) confirming this view. However, the melting temperature remains constant at ca. $165^{\circ} \mathrm{C}$ regardless of the cooling rate indicating the formation of a consistent crystalline phase distinct from the M-DPP. Moreover, the enthalpy for the melting phase transition of $\mathrm{H}$ $(D P P)_{2}$ is similar to that of M-DPP $\left(35 \mathrm{~J} \mathrm{~g}^{-1}\right.$ and $50 \mathrm{~J} \mathrm{~g}^{-1}$ respectively), which, contrary to the disparate scattering intensity observed by GIXRD, suggests that the horizontal linking strategy does not drastically reduce the crystallinity of the material. The different behaviour during the first heating scan is likely due to the effect of casting the materials from solvent, which results in a different self-assembly compared to freezing the melt. Indeed polymorph formation has been observed $^{61}$ in this class of materials even without the flexible linker.
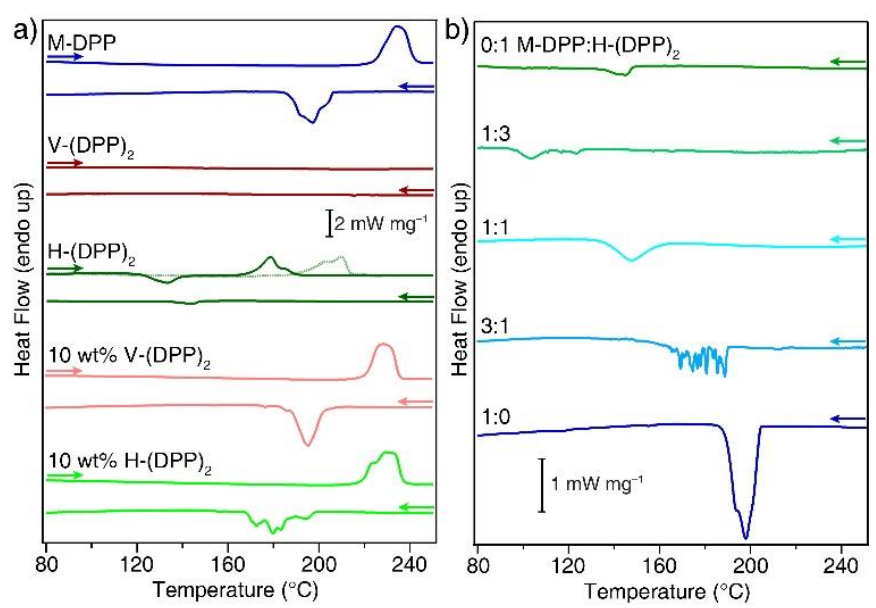

Figure 2. Differential scanning calorimetry of the dimer materials. (a) shows the second heating and cooling $\left(10^{\circ} \mathrm{C} \mathrm{min}-1\right)$ scans of M-DPP, V-(DPP) $)_{2} \mathrm{H}-(\mathrm{DPP})_{2}$ (the broken line in represents the first heating scan from a drop-cast sample), $10 \mathrm{wt} \% \mathrm{~V}-(\mathrm{DPP})_{2}$ in M-DPP and $10 \mathrm{wt} \% \mathrm{H}-(\mathrm{DPP})_{2}$ in M-DPP. (b) shows the second cooling only curves for blend samples of M-DPP:H-(DPP) ${ }_{2}$ in wt. ratios as indicated (where $0: 1$ represents pure dimer).

The different solid-state self-assembly of the two dimers compared to the parent molecule was next further probed by blending 10 wt\% of each dimer into M-DPP and examining the DSC. The second heating and cooling scans are shown in Figure $2 \mathrm{~d}$ and $2 \mathrm{e}$, respectively, for $10 \mathrm{wt} \% \mathrm{~V}-(\mathrm{DPP})_{2}$ and $10 \mathrm{wt} \% \mathrm{H}-$ $(\mathrm{DPP})_{2}$. The effect of blending the vertically-linked dimer into $\mathrm{M}$ DPP was minor: a slight melting point depression of $4^{\circ} \mathrm{C}$ to $220^{\circ} \mathrm{C}$ is noted, and the crystallization began $2^{\circ} \mathrm{C}$ earlier at $208^{\circ} \mathrm{C}$. However, the blend with $\mathrm{H}-(\mathrm{DPP})_{2}$ exhibited a significant freezing point depression of ca. $10^{\circ} \mathrm{C}$ and a complex 
supercooling behaviour. The effect of blending the $\mathrm{H}-(D P P)_{2}$ and M-DPP on the crystallization was further investigated by combining these two materials at different weight ratios. The second cooling scan is reported in Figure $2 f$ for each indicated M-DPP:H-(DPP) $)_{2}$ ratio. Interestingly, addition of $25 \mathrm{wt} \%$ of $\mathrm{M}$ DPP within $\mathrm{H}-(D P P)_{2}$ (i.e. a ratio of $1: 3$ ) also results in a depression in crystallization temperature of about $40^{\circ} \mathrm{C}$. Taking all of the blend ratio results of Figure $2 \mathrm{f}$ together shows that $\mathrm{M}$ DPP suppresses the crystallization of $\mathrm{H}-(D P P)_{2}$ while $\mathrm{H}-(D P P)_{2}$ also suppresses the crystallization of M-DPP. Such a behaviour cannot be rationalized with the view that both compounds solidify in the same crystal structure with different degrees in supercooling caused by kinetic limitations, as in such case the crystallization temperature would be expected to increase with the addition of M-DPP into the dimer matrix. Indeed the observed behaviour is consistent with colligative properties indicating that M-DPP and $\mathrm{H}$-(DPP $)_{2}$ form a solid solution upon blending with $\Delta \mathrm{H}^{\mathrm{mix}}>0$ and implying that pure $\mathrm{H}$-(DPP $)_{2}$ and $\mathrm{M}$ DPP self-assemble with different stacking motifs. Confirmation of the different crystal structure of $\mathrm{H}-(\mathrm{DPP})_{2}$ was next sought by preparing single crystals of $\mathrm{H}$-(DPP $)_{2}$ via the vapour diffusion crystal growth method. However, we were unable to form single crystals sufficiently large for X-ray analysis. Nonetheless, given the complexity of self-assembly in solution processed films (as indicated by the difference between the first and second heating scans of the $\left.\mathrm{H}-(\mathrm{DPP})_{2}\right)$, a single crystal sample would likely not be representative of the structures relevant to thin film charge transport. Nevertheless, the UV-Vis, GIXRD, and DSC results data taken together provide a clear picture that the horizontal linking strategy in the $\mathrm{H}-(\mathrm{DPP})_{2}$ dimer effectively achieves the goal of the study: to modulate the molecular selfassembly without changing the conjugated core elements of the semiconducting molecule. In contrast, the vertical linking strategy leads to a dimer with poor solubility and a drastically reduced self-assembly in the solid state.

To understand the effect of the molecular self-assembly on the electronic performance of the materials, the charge transport in solution processed thin films was measured by fabricating bottom-gate bottom-contact organic field effect transistors (OFETs). Table S1, ESI summarizes the main transistors characteristics, while device output characteristics and transfer curves are given in the ESI, Figures S4 and S5. As-cast M-DPP thin films gave hole mobility extracted from saturated regime $\left(\mu_{\mathrm{h}}\right)$ values similar to previously reported work $\left(10^{-5} \mathrm{~cm}^{2} \mathrm{~V}^{-1} \mathrm{~S}^{-}\right.$ 1), ${ }^{44}$ while $\mu_{\mathrm{h}}$ in pure $\mathrm{H}$-(DPP) $)_{2}$ films was found to be only slightly lower (see table S1, ESI). However, after thermally annealing at $110{ }^{\circ} \mathrm{C}$, the $\mu_{\mathrm{h}}$ for M-DPP increased by one order of magnitude, while $\mu_{\mathrm{h}}$ for $\mathrm{H}$-(DPP) $)_{2}$ was only enhanced by a factor of two. The increase in charge transport in M-DPP has been explained by Viterisi et al. who showed that strong intermolecular $\pi-\pi$ interactions at the benzofuran moiety act as a driving force for crystallization upon annealing. ${ }^{60}$ Reasonably, the aliphatic linker on the benzofuran moiety in $\mathrm{H}-(\mathrm{DPP})_{2}$ can kinetically hinder this $\pi-\pi$ stacking leading to a hole mobility which is less affected by thermal annealing. Neat $\mathrm{V}$-(DPP $)_{2}$ thin films exhibited a hole mobility lower than $10^{-6} \mathrm{~cm}^{2} \mathrm{~V}^{-1} \mathrm{~s}^{-1}$, which was attributed poor self-assembly of the resulting in ineffective intermolecular charge transport. Indeed, in previous studies the of a flexiblylinked polymeric M-DPP, the absence of thin-film self-assembly was also correlated to a poor OFET $\mu_{\mathrm{h}}{ }^{44}$ In addition the poor solubility of the $\mathrm{V}$-(DPP) 2 and the resulting poor thin film formation is also likely a factor in the poor mobility.

As distinct behaviour of the of $\mathrm{H}$ - and $\mathrm{V}-(\mathrm{DPP})_{2}$ dimers was observed by DSC when blending with M-DPP, we next sought to understand how this behaviour translates into differing charge transport characteristics. Figure 3 shows $\mu_{\mathrm{h}}$ as a function of the amount of dimer blended within films of M-DPP with as-cast and annealed devices. The values for the pure M-DPP are also shown (blue markers at 0 wt\%). Despite the established different self-assembly of the horizontally-linker dimer, its addition up to $10 \mathrm{wt} \%$ does not significantly alter $\mu_{\mathrm{h}}$. However, upon the addition of $25 \mathrm{wt} \%$, the annealed devices exhibit a reduced $\mu_{\mathrm{h}}$ approaching that of the pure (annealed) $\mathrm{H}-(\mathrm{DPP})_{2}$. In contrast, $\mathrm{V}$-(DPP $)_{2}$ addition up to $10 \mathrm{wt} \%$ results in an order of magnitude increase in $\mu_{\mathrm{h}}$ for both film conditions. Unfortunately, further increasing the amount of $\mathrm{V}$-(DPP $)_{2}$ resulted in a decrease in $\mu_{\mathrm{h}}$ which is attributed to the aforementioned poor crystallinity and film formation of the vertically-linked dimer.

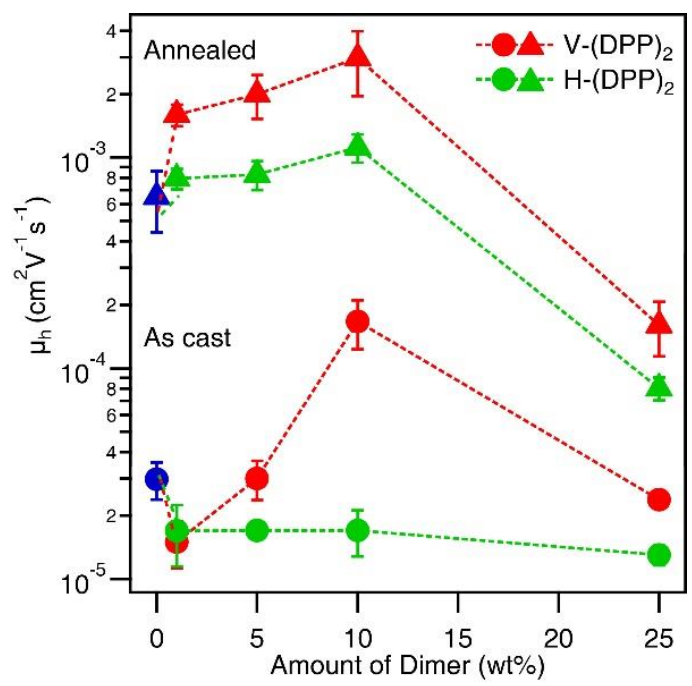

Figure 3. Average hole mobility $\left(\mu_{h}\right)$ extracted from saturated regime in OFET devices prepared with pure M-DPP (blue markers) and M-DPP blended with the dimer molecules $\mathrm{H}-(\mathrm{DPP})_{2}$ (green markers) and $\mathrm{V}-(\mathrm{DPP})_{2}$ (red markers). Circle markers represent values from as-cast thin films while triangles indicate values taken from devices annealed at $110^{\circ} \mathrm{C}$ for $10 \mathrm{~min}$.

Topographical analysis of the OFET thin films by Atomic force microscopy, AFM (Figure 4), gives plausible explanation for the behaviour of $\mu_{\mathrm{h}}$ with respect to the addition of the dimer molecules. While we note that AFM gives an impression of the morphology at the semiconductor/air interface, and not the structure of the buried semiconductor/dielectric interface (where charge transport occurs in the OFET device structure employed in this work) comparisons between morphology and charge transport are routine and can offer useful insight. In our case, the thin film morphology of the pure M-DPP film (Figure 4a) exhibits the expected haystack morphology with needle-like features ca. $1 \mu \mathrm{m}$ in length and $100 \mathrm{~nm}$ in width corresponding to crystal domains. ${ }^{44}$ The thin film with $10 \mathrm{wt} \% \mathrm{H}-(\mathrm{DPP})_{2}$, shown 
in Figure 4b, shows similarly sized features and an increase in RMS roughness from $2.25 \mathrm{~nm}$ (pure M-DPP) to $4.38 \mathrm{~nm}$ (10 wt\% $\mathrm{H}$-(DPP)). In contrast, the film with added V-(DPP) $)_{2}$ exhibits a much smoother surface (RMS $0.79 \mathrm{~nm}$ ) without needle-shaped domains (Figure 4c). Since grain-boundaries and void spaces between crystals grains are known to limit charge carrier transport though thin films, ${ }^{65}$ the reduced presence of grain boundaries in the film with the vertical dimer could reasonably explain the higher mobility, which is observed at optimum loading before the self-assembly is perturbed too much by the poorly crystalline dimer. Indeed, the DSC data of the M-DPP 10 $w t \%$ of $\mathrm{V}-(\mathrm{DPP})_{2}$ (Figure $2 \mathrm{~d}$ ) does show a sharper crystallization peak compared to the neat M-DPP, and a slightly earlier onset of crystallization. These features suggest that $\mathrm{V}-(\mathrm{DPP})_{2}$ may act as nucleation promotor, inducing a more homogeneous crystallization of the film, which is consistent with the AFM topography results. For the horizontally-linked dimer, we note that the topography of the pure $\mathrm{H}$-(DPP) ${ }_{2}$ film (see ESI Figure S6) shows a much smaller grain size (but does reveal features consistent with a semicrystalline film). The increased presence of grain boundaries in this case reasonably explains its lower mobility despite the substantial crystallinity. However, we cannot discount a reduced transfer integral (electronic coupling $)^{66}$ for intermolecular charge transfer that may result from the different molecular self-assembly.

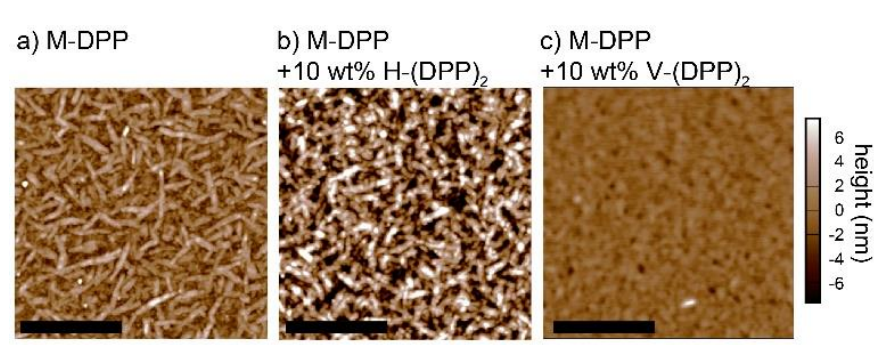

Figure 4. Atomic force microscopy height trace images (scale bars $2 \mu \mathrm{m}$ ) of annealed films containing M-DPP (a), and with 10 wt\% addition of (b) $\mathrm{H}-(\mathrm{DPP})_{2}$ and (c) V-(DPP)

Given the interesting behaviour of the dimers in OFET devices, we next sought to investigate their performance in bulk heterojunction OPVs. Devices were fabricated with $\mathrm{PC}_{61} \mathrm{BM}$ as the electron acceptor and a donor:acceptor ratio of 6:4. Current-voltage curves for representative devices after the standard annealing treatment $\left(110^{\circ} \mathrm{C}\right.$ for $\left.10 \mathrm{~min}\right)$ are shown in Figure 5. We note that all as-cast devices (tested before thermal annealing) performed poorly with short circuit current densities $\left(\mathrm{J}_{\mathrm{sc}}\right.$ ) of ca. 1-2 $\mathrm{mA} \mathrm{cm}^{-2}$ (see J-V curves for as-cast devices in Figure S7, ESI) similar to previously reported results. ${ }^{56}$ The standard M-DPP:PC ${ }_{61} \mathrm{BM}$ 6:4 device (dark blue curve Figure 5) reached a $J_{s c}$ of $9 \mathrm{~mA} \mathrm{~cm} \mathrm{~cm}^{-2}$ and a power conversion efficiency (PCE) of ca. $3.5 \%$ after the annealing treatment. We note that the state-of-the-art efficiency for this system has been reported above $4 \%$ using M-DPP, and the lower performances observed here can be attributed to the use of $\mathrm{PC}_{61} \mathrm{BM}$ instead of $\mathrm{PC} \mathrm{C}_{71} \mathrm{BM}$. Generally in the M-DPP:PCBM system, the enhancement upon annealing is known to be caused by a phase segregation of the donor and acceptor phases driven by the crystallization of the M-DPP. ${ }^{57}$ Optimum demixing results from this crystallization and creates a $\mathrm{BHJ}$ with a high interfacial surface area to afford high free charge carrier generation but also with continuous donor and acceptor phases for effective charge carrier transport. Adding a small amount (10 wt\%) of either of the dimers into the donor component in the $\mathrm{BHJ}$ did not significantly affect the J-V behaviour in our case as seen by the light blue and red J-V curves in Figure 5 (corresponding to $\mathrm{H}$ $(D P P)_{2}$ and $V-(D P P)_{2}$ addition, respectively). This is in contrast to the OFET results where the $10 \mathrm{wt} \%$ of $\mathrm{V}-(\mathrm{DPP})_{2}$ produced a change in thin film morphology and a large increase in charge carrier mobility after annealing. The different distances required for charge carrier transport $(100 \mathrm{~nm}$ in the OPV vs. 20 $\mu \mathrm{m}$ for the OFET) is likely the cause for this absence of any effect of the $\mathrm{V}$-(DPP $)_{2}$ addition. Indeed, grain-boundary limited charge transport is less likely to constrain the performance of the OPV given the thin active layer thickness.

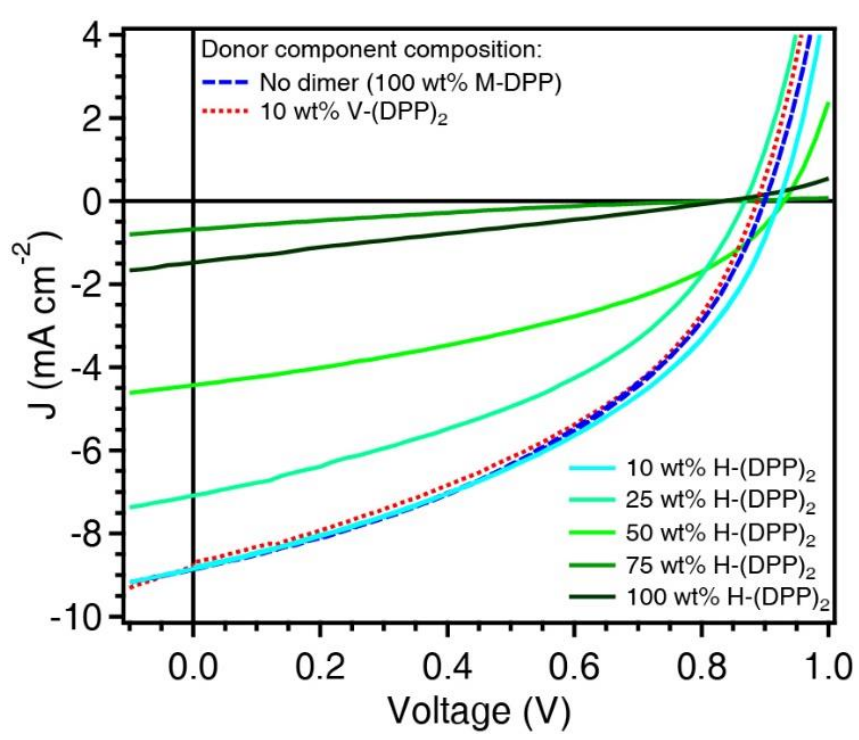

Figure 5. J-V curves of photovoltaic devices based on bulk heterojunction Donor:PC61BM at a weight ratio of 6:4. The donor component consists of M-DPP with added dimer as indicated. Devices were annealed at $110^{\circ} \mathrm{C}$.

Due to the poor solubility of the vertically linked dimer, OPV devices with higher fraction of $\mathrm{V}$-(DPP $)_{2}$ as an additive were not considered, however blends with increasing amounts of the horizontally linked dimer were tested. In the case of the OPV device with pure $\mathrm{H}-(\mathrm{DPP})_{2}$ as the donor phase (dark green curve in Figure 5) we found that the annealing step did not significantly affect the J-V-curve and the $\mathrm{J}_{\mathrm{sc}}$ remained at the low as-cast value of $1.5 \mathrm{~mA} \mathrm{~cm}^{-2}$. A small $\mathrm{J}_{\mathrm{sc}}$ which does not change upon annealing can either be due to a large degree of phase segregation (which limits free charge carrier generation) present in the as-cast device, or to the lack of crystallization of the $\mathrm{H}-(\mathrm{DPP})_{2}$ during the annealing conditions, leaving the blend in a well-mixed state which enhances charge carrier recombination. Since no large-scale phase segregation was observed in the film prepared with $\mathrm{H}$-(DPP) 2 (vide infra) the latter explanation is most reasonable. Indeed, blending of $\mathrm{H}$ $(\mathrm{DPP})_{2}$ into M-DPP in the donor component of the $\mathrm{BHJ}$ exhibited intermediate $\mathrm{J}_{\mathrm{sc}}$ 's after annealing, as shown in Figure 5, suggesting a tunable degree of phase segregation in the films is 
present after the thermal annealing. It is worth noting that the trend of the annealed $\mathrm{J}_{\mathrm{sc}}$ in function of the $\mathrm{H}-(\mathrm{DPP})_{2}$ content corresponds well with the trend observed in Figure $2 f$ for the DSC crystallization temperature. Indeed, the smallest $J_{S C}$ in the OPV devices is found to be at $75 \mathrm{wt} \% \mathrm{H}$-(DPP) $)_{2}$ (1:3 monomer to dimer), which also corresponds to the DSC curve showing the lowest crystallization temperature. The lower driving force for crystallization implied by the behaviour of this composition in the DSC results suggests that the $\mathrm{J}_{\mathrm{sc}}$ is the lowest in this device as the PCBM forms a well-mixed (non-phase segregated) active layer. To confirm the differing phase segregation in $\mathrm{H}$ $(\mathrm{DPP})_{2}:$ PCBM blends, solvent cast BHJs were further studied by DSC. Differences between the first and second heating scan from solvent cast $\mathrm{BHJ}$ s heating past the melting transitions are shown in Figure S8, ESI. Interestingly, when $\mathrm{H}-(\mathrm{DPP})_{2}$ is blended with $\mathrm{PCBM}$ over a wide range of composition, the donor melting transition is present on the first heating scan but disappears on the second heating. This is in contrast to M-DPP:PCBM blends where the melting transition is present also on the second heating scan, and thus indicates that the $\mathrm{H}-(D P P)_{2}$ has a relatively increased interaction with PCBM.

Even though phase segregation control using the $\mathrm{H}-(D P P)_{2}$ as an additive offers no improvement of the PCE in this system since an ideal $\mathrm{BHJ}$ can already be realized with the known optimized annealing treatment, it remains a potential tool to affect the thermodynamic equilibrium of the BHJ. Indeed, upon long thermal treatments the standard M-DPP:PCBM BHJ is known to further phase segregate, expelling the PCBM and leading to a drop in PCE. ${ }^{44}$ Moreover, the general lack of a detectable glass transition temperature in small molecule semiconductors ${ }^{67}$ means that the "cold crystallization" and continued phase segregation can occur at temperatures lower than the annealing temperature ${ }^{57}$ albeit at lower rates. This inherent morphological instability remains a key issue for the long-term stability of OPVs based on crystalline molecules. ${ }^{68}$

In initial experiments of the long-term annealing of BHJs with added dimers we noticed a significant qualitative difference in the morphology. Optical micrographs of the $\mathrm{BHJ}$ after annealing for 5 hours at $100^{\circ} \mathrm{C}$ with or without $10 \mathrm{wt} \%$ of either dimer are shown in Figure 6. Indeed, the neat film of $M$ DPP:PCBM exhibits dark aggregates that have previously been identified as phase-segregated PCBM domains. ${ }^{30}$ The BHJ prepared with $10 \mathrm{wt} \%$ of the $\mathrm{V}$-(DPP $)_{2}$ in the donor component phase also showed segregation under the same annealing conditions; however, the effect was slightly attenuated. Surprisingly, the $\mathrm{H}-(\mathrm{DPP})_{2}$ dimer showed no indication of any large-scale phase segregation, suggesting an improved $\mathrm{BHJ}$ thermal stability. It is worth noting that $10 \mathrm{wt} \% \mathrm{H}-(\mathrm{DPP})_{2}$ offers a more stable $\mathrm{BHJ}$ than $10 \mathrm{wt} \% \mathrm{~V}$-(DPP) $)_{2}$ despite its higher degree of crystallinity as observed from GIXRD and DSC data. This observation suggests an important role of the molecular packing of $\mathrm{H}-(\mathrm{DPP})_{2}$ for engineering the $\mathrm{BHJ}$ stability.

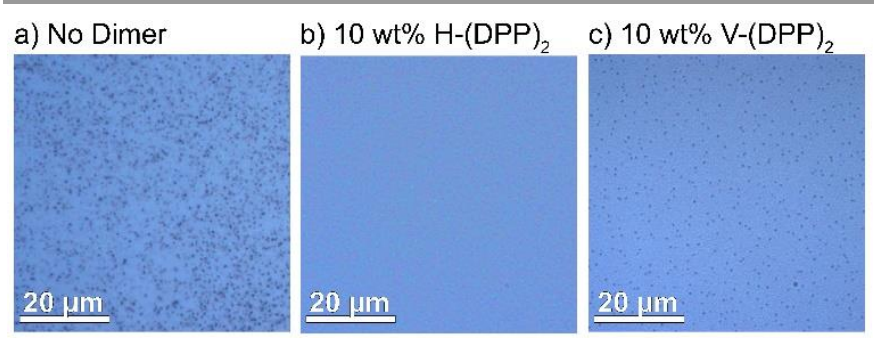

Figure 6. Optical microscopy images of thermally annealed $\left(5 \mathrm{~h} 100^{\circ} \mathrm{C}\right) \mathrm{M}-\mathrm{DPP}: \mathrm{PCBM}$ bulk-heterojunction thin-films (a) without added dimer and (b) with $10 \% \mathrm{wt}$. H-(DPP) and (c) with $10 \mathrm{wt} \% \mathrm{~V}-(\mathrm{DPP})_{2}$ included in the blend.

OPV devices prepared with 10 wt\% of either dimer and annealed after the top electrode deposition did not show significant difference in performance upon long-term annealing (See Figures S9 and S10, ESI). In all cases a significant decrease in PCE at short annealing times was observed with or without the dimer present. This decrease can be attributed to chemical degradation within the active layer due to reaction with the aluminium cathode. ${ }^{69}$ In order to decouple morphology changes from possible chemical instability in presence of the cathode, thermal annealing was performed prior to aluminium deposition for BHJs with $10 \mathrm{wt} \% \mathrm{H}-(\mathrm{DPP})_{2}$ dimer as the behaviour of this blend was found to be more promising in the optical micrographs presented in Figure 6. The PCE as a function of the active layer annealing time is presented in Figure 7.

As expected, the data demonstrate a faster as well as greater PCE loss for the OPV device prepared without the dimer, losing more than $50 \%$ of its original performance after 5 hours of annealing. However, devices containing $10 \mathrm{wt} \% \mathrm{H}-(\mathrm{DPP})_{2}$ exhibit only a slight loss in performance (about $10 \%$ ) after $5 \mathrm{~h}$ of annealing, retaining a PCE of $2.7 \%$. J-V curves corresponding to the devices are shown in the inset of Figure 7. As expected upon annealing, the change in PCE is correlated with a decrease in $\mathrm{J}_{\mathrm{sc}}$. This can be rationalized as a larger phase segregation leads to a smaller electron donor/acceptor interface possibly leading to larger exciton recombination. For BHJs without the dimer additive, a significant drop in $\mathrm{V}_{\text {oc }}$ also appears upon annealing. While a change in $V_{o c}$ is generally attributed to change in recombination, in this case, the $V_{\text {oc }}$ decrease is more likely caused by a smaller shunt resistance caused by the large phase segregation. This is supported by the dark J-V curves (see Figure S11, ESI) which clearly indicated a smaller resistance near shortcircuit conditions. Overall, these OPV device results demonstrate the advantage of morphological control over the $\mathrm{BHJ}$ via the $\mathrm{H}-(\mathrm{DPP})_{2}$ additive. 


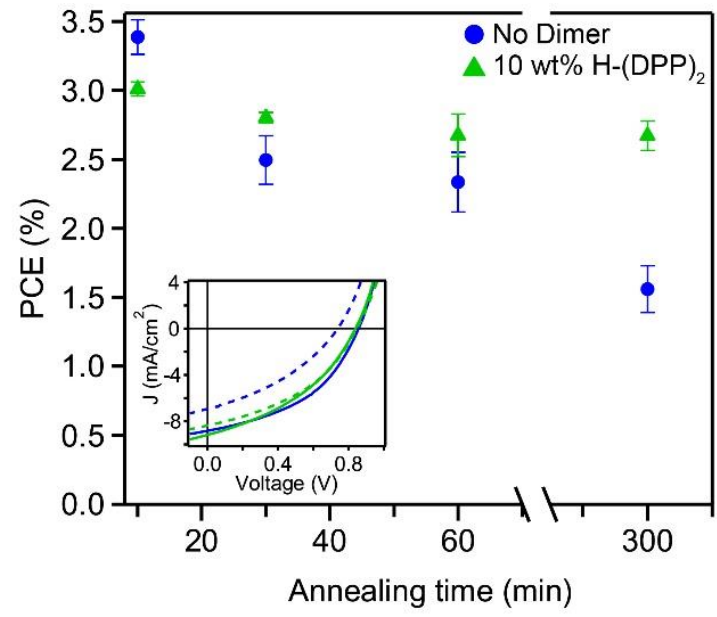

Figure 7. The OPV power conversion efficiency of M-DPP:PCBM devices with and without $10 \mathrm{wt} \% \mathrm{H}-(\mathrm{DPP})_{2}$ as a function of the active layer annealing time at $100{ }^{\circ} \mathrm{C}$. The inset shows J-V curves for M-DPP:PCBM for devices annealed for $10 \mathrm{~min}$ (solid lines) and $5 \mathrm{~h}$ (broken lines) with (green) and without (blue) addition of $10 \mathrm{wt} \% \mathrm{H}$-(DPP) 2 .

Altogether, the different behaviours of the dimers as additives in BHJ OPVs can be rationalized by their demonstrably different interactions with the parent M-DPP. The aforementioned nucleation promoting effects of the $\mathrm{V}-(\mathrm{DPP})_{2}$ dimer do not offer any significant improvement over the $\mathrm{BHJ}$ morphology obtained by optimized thermal annealing of the as-cast blend, and since this dimer at $10 \mathrm{wt} \%$ loading does not significantly hinder the ability of the M-DPP to crystallize, no important changes in OPV device performance are noted. On the other hand, from the DSC results the horizontally-linked dimer has a clear thermodynamic influence on the self-assembly of the M-DPP to crystallize. This effect reasonably translates into a reduced interaction parameter between the donor and acceptor in the blend ${ }^{70}$ and thus a reduced phase separation during annealing. While this does lead to a more stable bulk-heterojunction when $10 \mathrm{wt} \%$ of the $\mathrm{H}-(\mathrm{DPP})_{2}$ dimer is used in the donor phase, we note that an increased miscibility of the donor and acceptor is not necessarily beneficial for OPV operation. Indeed, the benefit of improved carriers charge separation implied with a well-mixed blend is offset by an increase in charge trapping, ${ }^{71}$ as previously mentioned, which reasonably explains the poor behaviour of the OPVs when the $\mathrm{H}-(\mathrm{DPP})_{2}$ dimer is purely used as the donor.

\section{Conclusions}

In this work we present a strategy directed toward increasing understanding of the effects of self-assembly of solutionprocessed molecular semiconductors on their optoelectronic properties. We designed two novel DPP(TBFu) ${ }_{2}$-based dimers using an aliphatic linker approach that allows retaining a welldefined conjugated core while also controlling the interactions and self-assembly of the semiconducting moiety. The "vertically-linked," V-(DPP) ${ }_{2}$, and the "horizontally-linked," $\mathrm{H}$ $(\mathrm{DPP})_{2}$, dimers were found to retain the optical band-gap of the parent DPP(TBFu $)_{2}$ molecule, but exhibit very different selfassembly properties. For $\mathrm{H}$-(DPP) 2 , solid-state UV-Vis, GIXRD and DSC data suggest the aliphatic linker partially lowers Van der Waals interaction between neighbouring conjugated cores while DSC data show only a slightly reduced melting enthalpy and a positive enthalpy of mixing between the horizontal dimer and the parent molecule, confirming a different solid state selfassembly. In contrast the vertically-linked dimer was poorly crystalline and likely acted as a nucleation promoter for the parent $\mathrm{DPP}(\mathrm{TBFu})_{2}$. Both dimers maintained ability to transport charge in OFET devices, although at a reduced hole mobility. Blends of $\mathrm{V}-(\mathrm{DPP})_{2}$ and the parent $\mathrm{DPP}(\mathrm{TBFu})_{2}$ showed an enhanced mobility by a factor of 5-10 in annealed and as-cast films, respectively, up to $3.0 \times 10^{-3} \mathrm{~cm}^{2} \mathrm{~V}^{-1} \mathrm{~s}^{-1}$ in the bottomcontact bottom-gate configuration. This increase was correlated to a change in thin film morphology, caused by the likely nucleation promotion effect of the dimer, where fewer large charge-trapping grain boundaries are observed but the crystallinity of the DPP(TBFu $)_{2}$ in the thin film remains present. In contrast, blends of $\mathrm{H}-(\mathrm{DPP})_{2}$ and the parent DPP(TBFu $)_{2}$, did not show a significant increase in hole mobility, but OPV devices including 10 wt\% of $\mathrm{H}-(\mathrm{DPP})_{2}$ in the donor phase yielded a significant increase in device stability under thermal stress (retaining $90 \%$ of the initial PCE after 5 hours compared to only $45 \%$ for the control). In this case, the increased thermodynamic miscibility between the donor and acceptor phases when including the $\mathrm{H}-(D P P)_{2}$ prevents large scale phase segregation. Overall, this work demonstrates that linking conjugated segments into dimers with a flexible aliphatic chain is a promising approach to control molecular self-assembly without changing the nature of the semiconducting molecular core. The linker position has a significant effect on the self-assembly of the resulting dimer, which in turn alters the optoelectronic properties in the solid state and gives insight into the effects of self-assembly apart from other factors. We demonstrate that by using dimers as additives in functional devices, either kinetic (i.e. likely nucleation promotion by the vertically-linker dimer) or thermodynamic (i.e. controlling the interactions of mixing with the horizontally-linker dimer) aspects of the molecular selfassembly can be tuned to offer unique control over the thin film morphology and device performance. Since our flexibly-linked dimer strategy is easily generalizable to a large set of solution processesable molecular semiconductors (given the ubiquitous present of aliphatic solubilizing chains), the extension of this concept to other systems will likely lead to an increased understanding of the important relation between molecular self-assembly and the performance of organic electronic devices.

\section{Experimental Section}

Synthetic procedures: Full synthetic procedures and characterization of the $\mathrm{V}-(\mathrm{DPP})_{2}$ and $\mathrm{H}-(\mathrm{DPP})_{2}$ dimers are given in the Electronic Supplementary Information (ESI).

Transistor fabrication and testing: Bottom-gate, bottomcontact FETs were fabricated using pre-patterned test substrates (Fraunhofer Institute for Photonic Microsystems) whose source and drain contacts were composed of a $30 \mathrm{~nm}$ thick gold layer on top of a $10 \mathrm{~nm}$ thick titanium adhesion layer. 
A $230 \mathrm{~nm}$ thick silicon oxide was used as gate dielectric and ndoped silicon wafer as the substrate and gate electrode. The channel length used was $20 \mu \mathrm{m}$, with a channel width of $1 \mathrm{~cm}$. The transistor substrates were cleaned by rinsing with acetone, deionized water, and isopropyl alcohol. After drying under nitrogen, the substrates were subsequently exposed to a nitrogen plasma for $15 \mathrm{~min}$. Films of ca. $60 \mathrm{~nm}$ thickness were spin-coated from $10 \mathrm{mg} \mathrm{mL}$ precursor solutions in chlorobenzene at $3000 \mathrm{rpm}$ for $1 \mathrm{~min}$. The solutions were prepared by dissolution at $80{ }^{\circ} \mathrm{C}$ overnight under continuous stirring. All solutions and films were prepared under argon atmosphere. Electronic testing of the FETs was carried out in a nitrogen atmosphere at RT using a custom-built probe station and a Keithley 2612A dual-channel source measure unit. Annealing was performed under nitrogen atmosphere. The field-effect mobility was extracted from the saturation region as presented in the ESI. Four devices were measured at each condition in order to report the average value.

Solar cell Fabrication and testing: Solar cells were fabricated on a glass substrate patterned with $300 \mathrm{~nm}$ of ITO. A $40 \mathrm{~nm}$ layer of PEDOT:PSS (Ossilla M121 Al 4083) was first spin coated at $3000 \mathrm{rpm}$ for $1 \mathrm{~min}$ prior to annealing at $130{ }^{\circ} \mathrm{C}$ in air. The $\mathrm{BHJ}$ active layer was then spin-cast under argon atmosphere at 3000 rpm from a solution of $\mathrm{DPP}(\mathrm{TBFu})_{2}$ and $\mathrm{PC}_{61} \mathrm{BM}$ in chlorobenzene at a total solid concentration of $20 \mathrm{mg} \mathrm{mL}^{-1}$. The active layers were determined to be ca. $100 \mathrm{~nm}$ thick using a Bruker Dektak XT profilometer. An $80 \mathrm{~nm}$ thick aluminum cathode was deposited (area $16 \mathrm{~mm}^{2}$ ) by thermal evaporation (Kurt J. Lesker Mini-SPECTROS). Electronic characterization was performed under simulated AM1.5G irradiation from a $300 \mathrm{~W}$ Xe arc lamp set to $100 \mathrm{~mW} \mathrm{~cm}^{-2}$ with a calibrated Si photodiode (ThorLabs). Current-voltage curves were obtained with a Keithley 2400 source measure unit. Device fabrication was performed under an argon atmosphere and testing was performed under nitrogen atmosphere.

Thermal characterization: Differential scanning calorimetry was performed using a Perkin-Elmer DSC8000 calibrated with indium and zinc at a scanning rate of $10{ }^{\circ} \mathrm{C} \mathrm{min}-1$. Samples were prepared by drop-casting from a precursor solution in chlorobenzene and slow evaporation of the solvent at $80{ }^{\circ} \mathrm{C}$ under argon atmosphere. Enthalpies were calculated by integrating over the phase transition.

X-ray diffraction characterization: XRD was measured with a D8 Discovery (Bruker) diffractometer using $\mathrm{Cu} K \alpha$ radiation and a $\mathrm{Ni} \beta$-filter with a scan rate of $0.05^{\circ} \mathrm{min}^{-1}$ and a step width of $0.01^{\circ}$. The sample was prepared by drop-casting the material on PEDOT-PSS and annealing at $110{ }^{\circ} \mathrm{C}$ for 30 minutes prior to measurements.

Atomic force microscopy characterization: AFM characterization was performed with an Asylum Research Cypher in AC mode using Atomic Force AC240TS tips.

\section{Acknowledgements}

The authors thank the European Research Commission (Project No. 336506, CEMOS) for financial support. The Authors thank
Loic Jeanbourquin from the laboratory of supramolecular chemistry at EPFL for his help in material characterization.

\section{Notes and references}

1 A. Mishra and P. Bäuerle, Angew. Chem. Int. Ed., 2012, 51, 2020-2067.

2 J. Roncali, P. Leriche and P. Blanchard, Adv. Mater., 2014, 26, 3821-3838.

3 P. M. Beaujuge and J. M. J. Fréchet, J. Am. Chem. Soc., 2011, 133, 20009-20029.

4 H. Yao, L. Ye, H. Zhang, S. Li, S. Zhang and J. Hou, Chem. Rev., 2016, 116, 7397-7457.

5 W. Ni, X. Wan, M. Li, Y. Wang and Y. Chen, Chem. Commun., 2015, 51, 4936-4950.

6 S. L. Price, Chem. Soc. Rev., 2014, 43, 2098-2111.

7 C.-F. Huang, S.-L. Wu, Y.-F. Huang, Y.-C. Chen, S.-T. Chang, T.Y. Wu, K.-Y. Wu, W.-T. Chuang and C.-L. Wang, Chem. Mater., 2016, 28, 5175-5190.

8 A. O. F. Jones, B. Chattopadhyay, Y. H. Geerts and R. Resel, Adv. Funct. Mater., 2016, 26, 2233-2255.

9 T. Wombacher, A. Gassmann, S. Foro, H. von Seggern and J. J. Schneider, Angew. Chem. Int. Ed., 2016, 55, 6041-6046.

10 M. Stolte, S.-L. Suraru, P. Diemer, T. He, C. Burschka, U. Zschieschang, H. Klauk and F. Würthner, Adv. Funct. Mater., 2016, 26, 7415-7422.

11 K.-Y. Wu, T.-Y. Wu, S.-T. Chang, C.-S. Hsu and C.-L. Wang, Adv. Mater., 2015, 27, 4371-4376.

12 Y.-C. Wu, P. Leowanawat, H.-J. Sun, B. E. Partridge, M. Peterca, R. Graf, H. W. Spiess, X. Zeng, G. Ungar, C.-S. Hsu, P. A. Heiney and V. Percec, J. Am. Chem. Soc., 2015, 137, 807-819.

13 Y. Diao, K. M. Lenn, W.-Y. Lee, M. A. Blood-Forsythe, J. Xu, Y. Mao, Y. Kim, J. A. Reinspach, S. Park, A. Aspuru-Guzik, G. Xue, P. Clancy, Z. Bao and S. C. B. Mannsfeld, J. Am. Chem. Soc., 2014, 136, 17046-17057.

14 B. Lee, Y. Chen, D. Fu, H. T. Yi, K. Czelen, H. Najafov and V. Podzorov, Nat. Mater., 2013, 12, 1125-1129.

15 O. V. Mikhnenko, M. Kuik, J. Lin, N. van der Kaap, T.-Q. Nguyen and P. W. M. Blom, Adv. Mater., 2014, 26, 1912-1917.

16 F. Liscio, C. Albonetti, K. Broch, A. Shehu, S. D. Quiroga, L. Ferlauto, C. Frank, S. Kowarik, R. Nervo, A. Gerlach, S. Milita, F. Schreiber and F. Biscarini, ACS Nano, 2013, 7, 1257-1264.

17 Y. Wu, A. R. Chew, G. A. Rojas, G. Sini, G. Haugstad, A. Belianinov, S. V. Kalinin, H. Li, C. Risko, J.-L. Brédas, A. Salleo and C. D. Frisbie, Nat. Commun., 2016, 7, 10270.

18 J. Rivnay, L. H. Jimison, J. E. Northrup, M. F. Toney, R. Noriega, S. Lu, T. J. Marks, A. Facchetti and A. Salleo, Nat. Mater., 2009, 8, 952-958.

19 H. Dong, X. Fu, J. Liu, Z. Wang and W. Hu, Adv. Mater., 2013, 25, 6158-6183.

20 J. Rivnay, S. C. B. Mannsfeld, C. E. Miller, A. Salleo and M. F. Toney, Chem. Rev., 2012, 112, 5488-5519.

21 W. Chen, M. P. Nikiforov and S. B. Darling, Energy Environ. Sci., 2012, 5, 8045-8074.

22 C.-H. Lee, G.-H. Lee, A. M. van der Zande, W. Chen, Y. Li, M. Han, X. Cui, G. Arefe, C. Nuckolls, T. F. Heinz, J. Guo, J. Hone and P. Kim, Nat. Nanotech., 2014, 9, 676-681. 
23 J. Mei, Y. Diao, A. L. Appleton, L. Fang and Z. Bao, J. Am. Chem. Soc., 2013, 135, 6724-6746.

24 Y. Diao, L. Shaw, Z. Bao and S. C. B. Mannsfeld, Energy Environ. Sci., 2014, 7, 2145-2159.

25 G. Giri, S. Park, M. Vosgueritchian, M. M. Shulaker and Z. Bao, Adv. Mater., 2014, 26, 487-493.

26 G. Giri, R. Li, D.-M. Smilgies, E. Q. Li, Y. Diao, K. M. Lenn, M. Chiu, D. W. Lin, R. Allen, J. Reinspach, S. C. B. Mannsfeld, S. T. Thoroddsen, P. Clancy, Z. Bao and A. Amassian, Nat Commun., 2014, 5, 3573.

27 C. Luo, A. K. K. Kyaw, L. A. Perez, S. Patel, M. Wang, B. Grimm, G. C. Bazan, E. J. Kramer and A. J. Heeger, Nano Lett., 2014, 14, 2764-2771.

28 Y. Diao, B. C. K. Tee, G. Giri, J. Xu, D. H. Kim, H. A. Becerril, R. M. Stoltenberg, T. H. Lee, G. Xue, S. C. B. Mannsfeld and Z. Bao, Nat. Mater., 2013, 12, 665-671.

29 Y. Yuan, G. Giri, A. L. Ayzner, A. P. Zoombelt, S. C. B. Mannsfeld, J. Chen, D. Nordlund, M. F. Toney, J. Huang and Z. Bao, Nat. Commun., 2014, 5, 3005.

30 M. R. Niazi, R. Li, E. Qiang Li, A. R. Kirmani, M. Abdelsamie, Q. Wang, W. Pan, M. M. Payne, J. E. Anthony, D.-M. Smilgies, S. T. Thoroddsen, E. P. Giannelis and A. Amassian, Nat. Commun., 2015, 6, 8598.

31 J. Mei and Z. Bao, Chem. Mater., 2014, 26, 604-615.

32 J. Y. Back, H. Yu, I. Song, I. Kang, H. Ahn, T. J. Shin, S.-K. Kwon, J. H. Oh and Y.-H. Kim, Chem. Mater., 2015, 27, 1732-1739.

33 I. Kang, H.-J. Yun, D. S. Chung, S.-K. Kwon and Y.-H. Kim, J. Am. Chem. Soc., 2013, 135, 14896-14899.

34 J. Lee, A. R. Han, H. Yu, T. J. Shin, C. Yang and J. H. Oh, J. Am. Chem. Soc., 2013, 135, 9540-9547.

35 L. Fang, Y. Zhou, Y.-X. Yao, Y. Diao, W.-Y. Lee, A. L. Appleton, R. Allen, J. Reinspach, S. C. B. Mannsfeld and Z. Bao, Chem. Mater., 2013, 25, 4874-4880.

36 Y. Wang, Y. Liu, S. Chen, R. Peng and Z. Ge, Chem. Mater., 2013, 25, 3196-3204.

37 Y. Sun, C. Zhang, B. Dai, B. Lin, H. Yang, X. Zhang, L. Guo and Y. Liu, J. Polym. Sci., Part A: Polym. Chem., 2015, 53, 1915-1926.

38 C. Zhang, Y. Sun, B. Dai, X. Zhang, H. Yang, B. Lin and L. Guo, Chin. J. Org. Chem., 2014, 34, 1701-1716.

39 K. Balakrishnan, A. Datar, T. Naddo, J. Huang, R. Oitker, M. Yen, J. Zhao and L. Zang, J. Am. Chem. Soc., 2006, 128, 73907398.

40 C. Wang, Y. Qin, Y. Sun, Y.-S. Guan, W. Xu and D. Zhu, ACS Appl. Mater. Interfaces, 2015, 7, 15978-15987.

41 P. E. Hartnett, E. A. Margulies, H. S. S. R. Matte, M. C. Hersam, T. J. Marks and M. R. Wasielewski, Chem. Mater., 2016, 28, 3928-3936.

42 J. Feng, W. Luo, T. Fang, H. Lv, Z. Wang, J. Gao, W. Liu, T. Yu, Z. Li and Z. Zou, Adv. Funct. Mater., 2014, 24, 3535-3542.

43 B. C. Schroeder, Z. Li, M. A. Brady, G. C. Faria, R. S. Ashraf, C. J. Takacs, J. S. Cowart, D. T. Duong, K. H. Chiu, C.-H. Tan, J. T. Cabral, A. Salleo, M. L. Chabinyc, J. R. Durrant and I. McCulloch, Angew. Chem. Int. Ed., 2014, 53, 12870-12875.

44 A. Gasperini, X. A. Jeanbourquin, A. Rahmanudin, X. Yu and K. Sivula, Adv. Mater., 2015, 27, 5541-5546.

45 Z. Liang, R. A. Cormier, A. M. Nardes and B. A. Gregg, Synth. Met., 2011, 161, 1014-1021.
46 X. Xiang, W. Shao, L. Liang, X.-Q. Chen, F.-G. Zhao, Z. Lu, W. Wang, J. Li and W.-S. Li, RSC Adv., 2016, 6, 23300-23309.

47 L. Ding, H.-B. Li, T. Lei, H.-Z. Ying, R.-B. Wang, Y. Zhou, Z.-M. Su and J. Pei, Chem. Mater., 2012, 24, 1944-1949.

48 X. Zhu, M. C. Traub, D. A. Vanden Bout and K. N. Plunkett, Macromolecules, 2012, 45, 5051-5057.

49 X. Lin, M. Hirono, T. Seki, H. Kurata, T. Karatsu, A. Kitamura, D. Kuzuhara, H. Yamada, T. Ohba, A. Saeki, S. Seki and S. Yagai, Chem. Eur. J., 2013, 19, 6561-6565.

50 A. Gasperini, S. Bivaud and K. Sivula, Chem. Sci., 2014, 5, 4922 4927.

51 W. Shao, L. Liang, X. Xiang, H.-j. Li, F.-g. Zhao and W.-s. Li, Chin. J. Chem., 2015, 33, 847-851.

52 B. C. Schroeder, Y.-C. Chiu, X. Gu, Y. Zhou, J. Xu, J. Lopez, C. Lu, M. F. Toney and Z. Bao, Adv. Electron. Mater., 2016, 2, 1600104-n/a.

53 Y. Zhao, X. Zhao, Y. Zang, C.-a. Di, Y. Diao and J. Mei, Macromolecules, 2015, 48, 2048-2053.

54 X. Zhao, Y. Zhao, Q. Ge, K. Butrouna, Y. Diao, K. R. Graham and J. Mei, Macromolecules, 2016, 49, 2601-2608.

55 Y. Zhao, X. Zhao, M. Roders, A. Gumyusenge, A. L. Ayzner and J. Mei, Adv. Mater., 2017, 29, 1605056.

56 B. Walker, A. B. Tamayo, X.-D. Dang, P. Zalar, J. H. Seo, A. Garcia, M. Tantiwiwat and T.-Q. Nguyen, Adv. Funct. Mater., 2009, 19, 3063-3069.

57 A. Sharenko, M. Kuik, M. F. Toney and T.-Q. Nguyen, Adv. Funct. Mater., 2014, 24, 3543-3550.

58 W. Li, M. Kelchtermans, M. M. Wienk and R. A. J. Janssen, J. Mater. Chem. A, 2013, 1, 15150-15157.

59 F. Proutiere and F. Schoenebeck, Angew. Chem. Int. Ed., 2011, 50, 8192-8195.

60 A. Viterisi, F. Gispert-Guirado, J. W. Ryan and E. Palomares, J. Mater. Chem., 2012, 22, 15175.

61 J. Liu, B. Walker, A. Tamayo, Y. Zhang and T.-Q. Nguyen, Adv. Funct. Mater., 2013, 23, 47-56.

62 O. P. Lee, A. T. Yiu, P. M. Beaujuge, C. H. Woo, T. W. Holcombe, J. E. Millstone, J. D. Douglas, M. S. Chen and J. M. J. Fréchet, Adv. Mater., 2011, 23, 5359-5363.

63 M. Kirkus, L. Wang, S. Mothy, D. Beljonne, J. Cornil, R. A. J. Janssen and S. C. J. Meskers, J. Phys. Chem. A, 2012, 116, 7927-7936.

64 M. M. J. Smulders, M. M. L. Nieuwenhuizen, T. F. A. de Greef, P. van der Schoot, A. P. H. J. Schenning and E. W. Meijer, Chem. Eur. J., 2010, 16, 362-367.

65 H. Klauk, Chem. Soc. Rev., 2010, 39, 2643-2666.

66 K. J. Thorley and C. Risko, J. Mater. Chem. C, 2016, 4, 38253832.

67 D. Rodriquez, S. Savagatrup, E. Valle, C. M. Proctor, C. McDowell, G. C. Bazan, T.-Q. Nguyen and D. J. Lipomi, ACS Appl. Mater. Interfaces, 2016, 8, 11649-11657.

68 I. Cardinaletti, J. Kesters, S. Bertho, B. Conings, F. Piersimoni, J. D'Haen, L. Lutsen, M. Nesladek, B. Van Mele, G. Van Assche, K. Vandewal, A. Salleo, D. Vanderzande, W. Maes and J. V. Manca, J. Photon. Energy, 2014, 4, 040997-040997.

69 M. Wang, F. Xie, J. Du, Q. Tang, S. Zheng, Q. Miao, J. Chen, N. Zhao and J. B. Xu, Sol. Energy Mater. Sol. Cells, 2011, 95, 33033310 . 
70 C. S. Kim, L. L. Tinker, B. F. DiSalle, E. D. Gomez, S. Lee, S. Bernhard and Y.-L. Loo, Adv. Mater., 2009, 21, 3110-3115.

71 B. P. Lyons, N. Clarke and C. Groves, Energy Environ. Sci., 2012, 5, 7657-7663. 